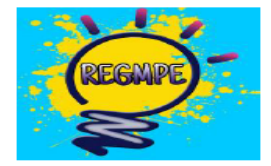

\title{
UNIVERSIDADE EMPREENDEDORA: ANÁLISE DE ESTRUTURAS E INICIATIVAS DE ESTÍMULO AO EMPREENDEDORISMO
}

\section{ENTREPRENEURIAL UNIVERSITY: ANALYSIS OF STRUCTURES AND INITIATIVES TO STIMULATE ENTREPRENEURSHIP}

\author{
Paula Karina Salume ${ }^{1}$ \\ Thiago Marques Rodrigues ${ }^{2}$ \\ Luis Renato Junqueira ${ }^{3}$ \\ Liliane de Oliveira Guimarães ${ }^{4}$
}

\begin{abstract}
RESUMO
As instituições de ensino superior exercem papel importante como geradoras de conhecimentos e tecnologias. Ainda assim é grande o volume de iniciativas empreendedoras malsucedidas, mesmo sendo as universidades um dos protagonistas no estímulo e apoio ao empreendedorismo. Nesse sentido, a presente pesquisa teve por objetivo levantar e comparar as estruturas e iniciativas das instituições de ensino superior que visam estimular o empreendedorismo. A partir de um estudo qualitativo e quantitativo, pretendeu-se detectar as ações empreendedoras das universidades e centros universitários com a intenção de buscar evidências que indicassem como as IES atuam nesse aspecto. Adicionalmente, averiguou-se, sob a perspectiva dos discentes de cursos de Administração, as condições das IES, por meio dos elementos ensino, pesquisa, extensão, infraestrutura e inovação para fortalecer a capacidade empreendedora dos alunos. Aplicou-se a estatística descritiva, correlação e "nuvens de palavras" para analisar os dados. Os resultados apontaram que há muito a ser feito para que os alunos percebam o envolvimento docente e da alta administração universitária no apoio ao empreendedorismo discente. Evidenciou-se ainda que o processo de desenvolvimento de mentalidade empreendedora nos discentes representa esforço conjunto dos atores institucionais, inclusive do próprio engajamento do aluno, que pela presente pesquisa, mostrou-se ínfimo.
\end{abstract}

\footnotetext{
${ }^{1}$ Docente na Universidade Federal de São João del-Rei (UFSJ) - Minas Gerais. paulasalume@ufsj.edu.br. https://orcid.org/0000-0003-1947-9608

2 Graduado pela Pontifícia Universidade Católica de Minas Gerais. thiagomrodrigues@live.com. https://orcid.org/0000-0002-9372-7887

${ }^{3}$ Docente na Pontifícia Universidade Católica de Minas Gerais. 1rjunq@gmail.com. https://orcid.org/0000-00026392-4791

${ }^{4}$ Docente na Pontifícia Universidade Católica de Minas Gerais. lilianeog@pucminas.br. https://orcid.org/00000002-3346-2207

Salume, P.K., Rodrigues, T.M., Junqueira, L.R., Guimarães, L.O.; Universidade empreendedora: análise de estruturas e iniciativas de estímulo ao empreendedorismo. Revista de Empreendedorismo e Gestão de Micro e Pequenas Empresas V.6, Nº1, p.01-22, Jan/Abr. 2021. Artigo recebido em 16/01/2021. Última versão recebida em 18/02/2021. Aprovado em 25/03/2021.
} 
Universidade empreendedora: análise de estruturas e iniciativas de estímulo ao empreendedorismo

Palavras-chave: Universidade Empreendedora; Cultura Empreendedora; Comportamento Empreendedor; Tríplice Hélice.

\begin{abstract}
The university and colleges play an important role as generators of knowledge and technologies. Even so, the volume of unsuccessful entrepreneurial initiatives is high, although the university is one of the protagonists in stimulating and supporting entrepreneurship. In this sense, this research aimed to survey and compare the structures and initiatives of higher education institutions that aim to stimulate entrepreneurship. Based on a qualitative and quantitative research, it was intended to detect how the entrepreneurial actions of universities and university centers are, in order to seek evidence that would indicate how universities act in this aspect. In addition, from the perspective of the students of the administration courses, the conditions of the universities were investigated, through the elements of teaching, research, extension, infrastructure and innovation to strengthen the entrepreneurial capacity of the students. Descriptive statistics, correlation and word cloud were applied to analyze the data. The results indicated that there is much to be done for students to realize the involvement of professors and university senior management in supporting student entrepreneurship. It was also evident that the process of developing an entrepreneurial mindset in students represents the joint effort of institutional actors, including the very engagement of the student, which by this research, proved to be negligible.
\end{abstract}

Keywords: Entrepreneurial University; Entrepreneurial Culture; Entrepreneurial Behavior; Triple Helix.

\title{
1. INTRODUÇÃO
}

As empresas têm exigido profissionais preparados e qualificados, atentos às mudanças do mercado e tecnológicas da sua área de atuação. Segundo Souza e Saraiva (2009), a crescente competição impõe muitos desafios às organizações e seus administradores, exigindo que decisões sejam tomadas de maneira mais célere, recursos sejam melhor utilizados e ações gerenciais que transformem informações em conhecimento para aumentar a competitividade organizacional. Nesse sentido, muito tem se discutido o papel das universidades no estímulo a iniciativas empreendedoras e na formação de profissionais capazes de resolver problemas e empreender. Para vários autores (Isenberg, 2011; Mason \& Brown, 2014; Tornatzky \& Rideout, 2014), as universidades representam um dos elementos, ou domínios, na terminologia de Isenberg (2011) que compõem o ecossistema empreendedor de determinada região ou território. Ou seja, juntamente com políticas públicas, instituições de suporte, características culturais, dentre outros elementos, são responsáveis por criar condições favoráveis aos negócios. Na visão desses autores, a contribuição das instituições universitárias para um ecossistema robusto é muito relevante, na medida em que é geradora de conhecimento, desenvolve, a partir das 
Universidade empreendedora: análise de estruturas e iniciativas de estímulo ao empreendedorismo

pesquisas realizadas, novas tecnologias, qualifica jovens para o mercado de trabalho ou para empreenderem.

Pesquisa realizada pelo Serviço Brasileiro de Apoio às Micro e Pequenas Empresas SEBRAE (2011) aponta que cerca de 1,2 milhão de novos empreendimentos são criados, sendo que $99 \%$ são micro e pequenas empresas. Referente aos novos empreendimentos, cerca de $73,1 \%$ sobrevivem somente até dois anos, ou seja, a grande maioria dos empreendedores estão despreparados para enfrentar as dificuldades inerentes ao processo empreendedor.

Nesse contexto - grande volume de iniciativas empreendedoras malsucedidas e universidades como um dos protagonistas no estímulo e apoio ao empreendedorismo - que esse artigo se insere. A pesquisa que foi base para elaboração do artigo teve por objetivo levantar e comparar as estruturas e iniciativas das instituições de ensino superior que visam estimular o empreendedorismo. A partir de um estudo qualitativo e quantitativo, pretendeu-se detectar as ações empreendedoras das universidades e centros universitários com a intenção de buscar evidências que indiquem como as IES atuam nesse aspecto. Adicionalmente, averiguou-se, sob a perspectiva dos discentes de cursos de Administração, as condições das IES, por meio dos elementos ensino, pesquisa, extensão, infraestrutura e inovação para fortalecer a capacidade empreendedora dos alunos.

De maneira geral, o objetivo foi entender como e se as instituições de ensino superior de Belo Horizonte têm assumido o que Etzkowitz (2003, 2004) denomina de terceira missão, ou seja, desenvolvimento de ações mais efetivas de estímulo e apoio ao empreendedorismo, tendo como decorrência, maior contribuição para o desenvolvimento social e econômico das regiões onde estão inseridas.

$\mathrm{O}$ artigo foi estruturado em cinco seções, além dessa introdução. Na segunda seção, nominada "Revisão da literatura", buscou-se discutir, sinteticamente, assuntos relacionados ao empreendedorismo e universidade empreendedora. Outra seção foi oportuna para apresentar os procedimentos metodológicos utilizados na pesquisa. A quarta seção foi criada para expor os resultados da pesquisa e discuti-los. Por fim, na quinta e última seção, as considerações finais do trabalho são apresentadas com foco nas principais conclusões da pesquisa e nos objetivos atingidos, além das limitações do estudo e das sugestões para novos trabalhos. 
Universidade empreendedora: análise de estruturas e iniciativas de estímulo ao empreendedorismo

\section{REVISÃO DE LITERATURA}

\subsection{UNIVERSIDADE EMPREENDEDORA}

O empreendedorismo contempla habilidades que podem ser transmitidas em forma de conhecimento e cabe às instituições de ensino superior carregarem esse papel para a sociedade, formando profissionais com postura de empreendedor para atuar no mercado econômico (Dornelas, 2016). As instituições de ensino superior começam a ter um papel primordial à medida em que assumem a função como geradora de novas indústrias e empresas, sendo assim, seu papel na sociedade se assemelha, em questão de importância, com o do governo e da indústria (Etzkowitz \& Zhou, 2017).

Volles, Gomes e Parisotto (2017) definem universidade empreendedora como aquela capaz de criar uma direção estratégica a seguir, formulando objetivos acadêmicos claros e transformando o conhecimento adquirido em valor econômico e social. As instituições de ensino superior apresentam um ambiente ideal para inovações, conhecimento e capital intelectual, no qual, os estudantes possuem grandes potenciais empreendedores.

Para Andrade e Torkomian (2001), a educação empreendedora é processo de transformação do ser humano no que diz respeito à identificação e aproveitamento de oportunidades, as quais, posteriormente, transformarão em realidade, contribuindo assim para a geração de valores financeiros, sociais e culturais para toda a sociedade. Conforme Audretsch (2014), as universidades possuem capacidade de transmitir seu conhecimento ao auxiliar as empresas e influenciar o empreendedorismo na sociedade. Essa transmissão se dá pela estratégia utilizada na relação entre universidade, governo e empresa, também conhecida como tríplice hélice.

\subsection{TRÍPLICE HÉLICE}

À medida que a sociedade se integra em conhecimento, as empresas transformam suas características, principalmente na admissão de novos funcionários, sendo assim, tornando-se cada vez mais rigorosa em relação à capacitação, o que ocasiona em uma demanda constante por profissionais que sejam capazes de lidar com diversas situações. Segundo Audy (2011), a sociedade por sua vez, começa a demandar mais das universidades e centros universitários uma solução para o desenvolvimento econômico social, isso devido a suas necessidades e exigências que o mercado possui.

REGMPE, Brasil-BR, V.6, Nº1, p. 01-22, Jan./Abr.2021 www.revistas.editoraenterprising.net Página 4 
Universidade empreendedora: análise de estruturas e iniciativas de estímulo ao empreendedorismo

Existem alguns modelos que estabelecem a relação entre governo, empresas e universidades. Um deles, conhecido como modelo estático, propõe que governo se envolva e controle as relações entre as universidades e empresas, ou seja, as universidades não têm ligação com as indústrias e para implementar uma pesquisa é necessária uma decisão do governo.

Segundo Etzkowitz e Zhou (2017), a indústria e a universidade, nesse modelo, estão subordinadas ao governo, cabendo ao estado assumir projetos e fornecer recursos para pesquisas. Sobre esta perspectiva, as indústrias e as universidades são vistas como dependentes do governo. Durante o regime militar no Brasil, o governo realizou investimentos pesados para a criação de novos centros de tecnologias, por exemplo, áreas relacionadas ao militarismo, indústrias de tecnologia, informática e telecomunicação.

Já o modelo "laissez-faire" pressupõe que o estado não deve interferir no funcionamento das relações entre empresa e universidade, limitando-se apenas, em criar leis que protejam os consumidores e os direitos de propriedades. Nesse esquema, as esferas institucionais apresentam-se individuais e independentes.

Conforme Etzkowitz e Zhou (2017), o papel da universidade em relação às empresas consistem em apenas fornecer o conhecimento em forma de artigos publicados, além de profissionais já graduados com conhecimentos em suas áreas específicas. Por outro lado, as empresas não criam expectativas em relação a novas descobertas e tecnologias, a qual, a mesma, sairia favorecida. A função do governo é de regulamentar, mas, caso haja algum problema no mercado, o mesmo deve atuar com o intuito de solucionar a falha existente no mesmo, sendo assim, investindo recursos financeiros em pesquisas nas universidades.

Na Figura 1, nota-se um modelo de simbiose entre geração de inovação, em que o mesmo se deriva da tripla hélice citada por Etzkowitz e Leydesdorff (2000), no qual gera uma base de conhecimento mais sólida e integrada. Na intersecção entre os autores, se estabelecem as condições para o desenvolvimento de uma relação produtiva de conhecimento. O governo começa a articular e estimular essas parcerias e, principalmente, não controlar tais relações. Essa interação em que os três autores apresentam têm importância para a geração de novas tecnologias, transmissão de conhecimento, crescimento econômico e, principalmente, desenvolvimento social. 
Universidade empreendedora: análise de estruturas e iniciativas de estímulo ao empreendedorismo

\section{Figura 1}

Governo Empresa e Universidade Modelo Tríplice Hélice da relação UEG

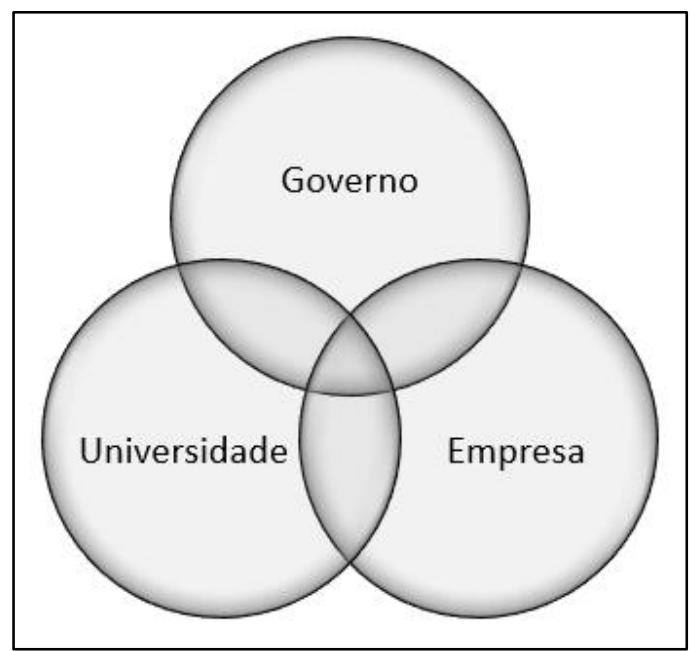

Nota. Fonte: Elaborado pelos autores, a partir de Audy (2011).

A interpretação do modelo da tríplice hélice indica que mudanças internas em cada hélice, oriundas do desenvolvimento de estratégias, incentivam a cooperação entre empresas concorrentes, resultando no desenvolvimento econômico e social, assim como, incumbência para as universidades, e o governo, passando apenas a articular o mercado deixando o controle e a direção das relações do mercado.

O modelo conceitual da tríplice hélice apresenta as seguintes características:

a) Cada hélice representada reconhece a sua influência nas ações dos demais. Podem citar as transferências de tecnologia e inovação por parte das universidades e centros universitários, legislação e regulamentação nas áreas de propriedade intelectual por parte do governo;

b) Novas formas de relacionamento criadas entre empresa, governo e universidades, por exemplo, alianças estratégicas, rede de cooperação e outros;

c) A interação entre universidade, governo e empresa, gerando benefícios para a sociedade.

Conforme Audy (2011), as universidades deixam de ser apenas instituições de ensino e se tornam instituições que combinam seus recursos potenciais na área de pesquisa com uma nova missão, voltadas para desenvolvimento econômico e social do local onde atua, promovendo, assim, um ambiente de inovações e transmissão de tecnologia, estimulando a produção de conhecimentos empreendedores. 
Universidade empreendedora: análise de estruturas e iniciativas de estímulo ao empreendedorismo

\subsection{QUALIDADE NA TRANSFERÊNCIA DE TECNOLOGIA}

Os avanços tecnológicos e científicos nas últimas décadas criaram um envolvimento da humanidade nas tecnologias. Segundo autores como Rodrigues e Tontini (1997), os avanços e a evolução dos sistemas de produção provocaram mudanças no foco das organizações, principalmente no processo de desenvolvimento de produtos e serviços. Hoje, várias universidades e centros universitários, assim como todas as outras organizações, estão sendo afetadas pelo ritmo avançado da globalização, evolução tecnológica e aumento da exigência dos clientes pela qualidade a ser adquirida em produtos ou serviços. Várias instituições de ensino superior estão oferecendo cursos à distância via rede de computadores, ampliando seu mercado para regiões e países diferentes, contudo, a competição por professores e pesquisadores de alta qualificação está cada vez mais acirrada devido à sua quebra de barreiras entre tais fronteiras. De acordo com Rodrigues e Tontini (1997), é necessária a inclusão de novas características empreendedoras, principalmente na compreensão em profundidade de seu papel no desenvolvimento econômico da sociedade.

Um dos principais componentes do valor percebido pelos consumidores em relação às universidades e centros universitários, de acordo com Rodrigues e Tontini (1997), é a qualidade do ensino. Uma excelente transmissão de conhecimento, tecnologia nos produtos e serviços prestados pelas instituições de ensino superior revertem-se em pesquisas e em consultorias para empresas e governo, além de gerar um maior número de matrículas, alunos qualificados e preparados para o mercado, possibilitando a cobrança de mensalidades mais caras devido ao serviço prestado à sociedade. Para as instituições de ensino superior, a qualidade é percebida como valor agregado na medida em que seus clientes estão dispostos a investir e pagar pelos seus serviços prestados. Neste sentido, a qualidade pode ser apresentada por duas dimensões básicas: capacidade de criar conhecimento e efetividade de transferência de tecnologia e ensino.

Conforme Rodrigues e Tontini (1997), ao compor esses dois elementos em eixos ortogonais, pode-se classificar as instituições de ensino superior em quatro níveis conforme mostra a figura 2 . 
Universidade empreendedora: análise de estruturas e iniciativas de estímulo ao empreendedorismo

\section{Figura 2}

Tipologia universitária por qualidade ou valor agregado

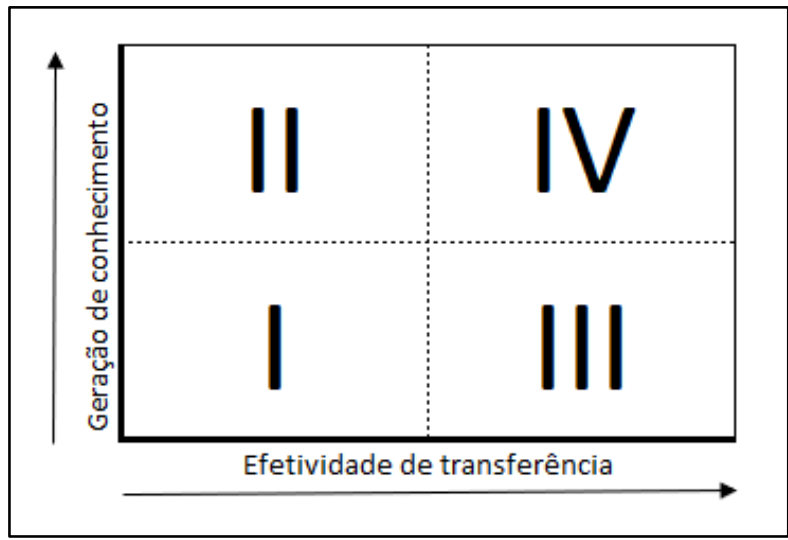

Nota. Fonte: Elaborado pelos autores, a partir de Rodrigues e Tontini (1997).

No que se refere ao primeiro quadrante, encontram-se as instituições de ensino superior centradas somente no ensino, sem estrutura ou ênfase em pesquisas, pouca capacitação dos professores e baixa tecnologia na transmissão de conhecimentos. Com os avanços tecnológicos, tais instituições encontram-se na inércia, permanecendo ultrapassadas (comparando com as concorrentes), sendo assim, são consideradas de baixo valor agregado pelos seus consumidores diretos e indiretos.

No que tange ao segundo quadrante, os autores Rodrigues e Tontini (1997) apresentam as instituições de ensino que desenvolvem pesquisas. Estas, por sua vez, geralmente abrangem um quadro de professores qualificados, boas estruturas para pesquisas e compreendem que tal prática é de suma importância para a instituição. Todavia, as instituições não apresentam métodos modernos de transmissão de ensino, além de não contar com artifícios eficientes para a transmutação de tecnologia e dos conhecimentos desenvolvidos pela mesma através da pesquisa para a sociedade onde atua.

Sob a luz da interpretação contida no terceiro quadrante, Rodrigues e Tontini (1997) expõem as instituições com pouca ênfase em pesquisa, entretanto, apresentam meios modernos de transmissão, principalmente por parte de professores instruídos e preparados. Apesar de seu sucesso no passado, tal modelo de ensino apresenta sinais de fraqueza, tal mácula é por conta da velocidade e evolução do conhecimento, no qual, atualmente, exige uma erudição mais especializada dos profissionais. Esta cognição apenas pode ser adquirida através de pesquisas e que tenham relações com a sociedade, assim como, o mercado econômico.

No IV quadrante, encontram-se as categorias de instituições com boa capacidade e geração de conhecimento. Essas instituições obtêm grandes relações exitosas com pesquisas e ensino, além de terem grande eficiência na transmissão de conhecimentos para a sociedade. REGMPE, Brasil-BR, V.6, Nº1, p. 01-22, Jan./Abr.2021 www.revistas.editoraenterprising.net Página 8 
Universidade empreendedora: análise de estruturas e iniciativas de estímulo ao empreendedorismo

Tais instituições promovem averiguações direcionadas para as necessidades dos clientes e do mercado, além de serem consideradas de alto valor agregado. As instituições alocadas nessa divisão apresentam as seguintes características de indicadores de empreendedorismo:

a) Cultura empreendedora: trabalham conforme as regras da instituição, estimulam a busca por recursos, respeitam o comportamento empreendedor e realizam atividades fora dos centros universitários (Clark, 2003). Essas instituições possuem maior proatividade para resolver problemas, aceitando os riscos presentes e aproveitando as oportunidades surgidas em seu meio.

b) Extensão: projeto no qual as universidades transmitem os seus conhecimentos adquiridos em pesquisas e ensinos ao público externo.

c) Inovação: é um fruto contínuo de pesquisa com a intenção de obter novos conhecimentos e tecnologias (Audy, 2017).

d) A infraestrutura adequada: é um dos indicadores em que permitem à instituição de ensino a realização de pesquisas e desenvolvimento de atividades.

e) Investimento financeiro: pesquisas e iniciativa inovadora requerem das instituições um investimento financeiro, assim, cobrindo todos os custos e despesas gastas na mesma.

As características apontadas pelas instituições de ensino superior remetem aos alunos uma capacidade empreendedora e qualificada para o mercado. Segundo uma pesquisa realizada pela Endeavor juntamente com o Serviço Brasileiro de Apoio às Micros e Pequenas Empresas (2016), 5,7\% dos alunos já empreendem, $21 \%$ pensam em empreender no futuro e 73,3\% não têm interesse em abrir um negócio. Segundo Bronoski (2008), a razão mais apontada por alunos de instituições de nível superior, os quais optaram em abrir um próprio negócio foi a liberdade para tomar suas decisões, aplicar os conhecimentos obtidos durante o período de graduação, recusa da hierarquia e a possibilidade de maiores ganhos financeiros. Pode-se observar que as instituições de ensino superior devem estar preparadas e capacitadas para formar profissionais capazes de lidar com diversas situações do mercado, além de incentivar a criar produtos e alimentar os sonhos dos alunos que queiram ter seu próprio negócio.

\section{PERCURSO METODOLÓGICO}

O presente trabalho objetivou levantar e comparar as estruturas e iniciativas das instituições de ensino superior que visam estimular o empreendedorismo. Para cumprir o REGMPE, Brasil-BR, V.6, Nº1, p. 01-22, Jan./Abr.2021 www.revistas.editoraenterprising.net Página 9 
Universidade empreendedora: análise de estruturas e iniciativas de estímulo ao empreendedorismo

objetivo proposto, adotou-se a abordagem de pesquisa qualitativa e quantitativa. No que diz respeito à primeira, realizaram-se pesquisas bibliográficas alicerçadas em artigos científicos que possibilitaram um referencial teórico esclarecedor, assim como uma pesquisa de informações nos meios de comunicação e sites das instituições investigadas, acerca de iniciativas empreendedoras.

Com o propósito de alcançar dados e informações no tocante ao problema em que se busca respostas, foi feita pesquisa de campo para obtenção dos dados primários. Para Vergara (2000), a pesquisa de campo decorre no local do acontecimento de certo fenômeno. As informações advindas da pesquisa de campo obtêm correlação e vinculação com a problemática instaurada de que as IES oferecem elementos que estimulem o comportamento empreendedor de seus estudantes.

A coleta de dados foi realizada nos centros universitários e universidades da região de Belo Horizonte que oferecem curso de Administração presencial, quais sejam: Centro Universitário Estácio de Sá, Centro Universitário Metodista Izabela Hendrix, Centro Universitário Newton Paiva, Centro Universitário Una, Centro Universitário Unihorizontes, Centro Universitário de Belo Horizonte (UNIBH), Pontifícia Universidade Católica de Minas Gerais (PUC Minas) e Universidade FUMEC.

Em um universo de 6.903 alunos matriculados em cursos de Administração presencial em centros universitários e universidades localizadas na cidade de Belo Horizonte - Minas Gerais (Brasil, 2017), aplicou-se a amostragem probabilística, com adoção de intervalo de confiança de $90 \%$ e margem de erro de 5\%, gerando uma amostra de 270 alunos.

O instrumento de coleta de dados foi composto por 22 questões objetivas e discursivas apresentadas aos entrevistados, no intuito de compor o material necessário para análise de dados. As questões abordadas contemplaram aspectos tais como apoio ao empreendedorismo universitário, infraestrutura da IES, postura empreendedora do discente e do docente.

Uma das principais fases de qualquer pesquisa é a análise de dados, que, para Dencker (2000), tem o objetivo de reunir as observações de maneira coerente e organizada, de forma que seja possível responder ao problema de pesquisa. A interpretação busca um sentido mais amplo aos dados coletados, fazendo a ponte entre eles e o conhecimento existente. A análise dos dados dessa pesquisa foi realizada por meio de estatística descritiva, análise da correlação entre fatores e nuvens de palavras. Segundo Bussab e Morettin (2013), estatística descritiva é utilizada para descrever e resumir os dados no intuito de melhor interpretação dos mesmos. Já a correlação, de acordo com Martins e Domingues (2019), determina a força do relacionamento 
Universidade empreendedora: análise de estruturas e iniciativas de estímulo ao empreendedorismo

entre dois fatores. Por fim, a ferramenta "nuvens de palavras" destaca o tamanho da fonte de acordo com a frequência em que uma palavra foi citada por diferentes entrevistados.

Foi elaborada a seguinte legenda para fins de apresentação dos resultados.

Tabela 1

Legenda para apresentação dos dados

\begin{tabular}{llll}
\hline Código & IES & Código & IES \\
\hline X1 & ESTÁCIO & X5 & PUC MINAS \\
X2 & FUMEC & X6 & UNA \\
X3 & IZABELA HENDRIX & X7 & UNI BH \\
X4 & NEWTON PAIVA & $\mathrm{X} 8$ & UNIHORIZONTES \\
\hline
\end{tabular}

Nota. Fonte: Elaborada pelos autores (2020).

\section{APRESENTAÇÃO E DISCUSSÃO DOS RESULTADOS}

A pesquisa foi realizada com 270 alunos do curso de administração das instituições de ensino superior da região de Belo Horizonte, dos quais 131 são do gênero feminino, 138 do grupo masculino e 1 preferiu não declarar seu gênero.

A tabela 2 evidencia a perspectiva dos discentes em relação ao envolvimento com iniciativas empreendedoras.

Tabela 2

Apoio ao empreendedorismo universitário

\begin{tabular}{lccc}
\hline Questão abordada & Sim & Não & Não sei \\
\hline $\begin{array}{l}\text { De modo geral, os estudantes em sua Universidade exercem ou estão } \\
\text { envolvidos com atividades empreendedoras? }\end{array}$ & $30,74 \%$ & $22,96 \%$ & $46,30 \%$ \\
\hline
\end{tabular}

Nota. Fonte: Dados da pesquisa.

Quando indagados sobre o envolvimento dos discentes com atividades empreendedoras apenas 30,74\% concordaram com a afirmativa apresentada. Em contrapartida, 22,96\% dos discentes entrevistados discordam e 46,30\% não souberam opinar. Nota-se que há um baixo envolvimento dos alunos com iniciativas empreendedoras. Fato que parece surpreender, uma vez que se refere a um ambiente, que é o da IES, em que se espera encontrar um comportamento contrário, ainda mais em se tratando de alunos de um curso de Administração, que são estimulados, em sua formação, a desenvolverem a capacidade de criar e gerir novos negócios ou de inovarem em negócios já existentes. Tal constatação leva à uma reflexão importante: em que medida as IES têm feito um trabalho de conscientização para uma mudança de mentalidade (mindset) do aluno, considerando o futuro do trabalho e das organizações? Por outro lado, por 
Universidade empreendedora: análise de estruturas e iniciativas de estímulo ao empreendedorismo

que os discentes, mesmo conscientes dos benefícios que uma atitude empreendedora pode provocar, não têm sido atuantes nesse ecossistema?

Segundo Bronoski (2008), os alunos do curso de Administração apresentam uma maior média de vocação empreendedora em relação aos demais cursos superiores, pois, as disciplinas apresentadas no decorrer do curso abordam conteúdos específicos relacionados aos conhecimentos, habilidades e competências, dando ênfase nas áreas empresariais, além de temáticas específicas ligadas ao empreendedorismo.

Apenas 6,67\% dos alunos concordam totalmente que a instituição teve participação fundamental no crescimento de projetos realizados pelos discentes. Outro fato relevante é que somente $11,85 \%$ dos alunos concordam totalmente com a afirmação de que a IES em que estuda influenciou positivamente a sua postura empreendedora. Em outro extremo, apenas 1,5\% afirmam que a instituição não teve relação alguma na sua postura empreendedora. Tais resultados parecem convergir para uma posição neutra, na qual o papel da IES é indiferente na formação do aluno, no que tange ao desenvolvimento de uma mentalidade empreendedora.

Quando indagados sobre a postura de seus professores, $18,89 \%$ dos alunos entrevistados concordaram totalmente que os mesmos possuem postura empreendedora, dinâmica e arrojada, ao passo que $1,48 \%$ dos discentes discordam totalmente da afirmação apresentada. Os pensamentos inovadores e criativos, na visão dos discentes, contabilizam apenas $8,14 \%$ em concordância total com a afirmação proposta.

Segundo Rodrigues e Tontini (1997), a infraestrutura das IES é responsável por ajudar os alunos a terem um bom desempenho em pesquisas, além de colaborar com os mesmos no seu próprio desenvolvimento profissional. Por meio da utilização da escala de 5 pontos, a qual 1 representa o adjetivo "péssimo" e 5 "excelente", obteve-se a opinião dos discentes acerca da infraestrutura disponibilizada pelas instituições de ensino superior. A tabela 3 retrata os resultados.

Tabela 3

Infraestrutura da IES

\begin{tabular}{lccccccccccc}
\hline Atributos/Instituições & $\mathbf{X 1}$ & $\mathbf{X 2}$ & $\mathbf{X 3}$ & $\mathbf{X 4}$ & $\mathbf{X 5}$ & $\mathbf{X 6}$ & $\mathbf{X 7}$ & $\mathbf{X 8}$ & $\begin{array}{c}\text { Média } \\
\text { por } \\
\text { atributo }\end{array}$ & $\begin{array}{c}\text { Desvio } \\
\text { Padrão }\end{array}$ \\
\hline Espaços abertos ou de convivência & 3,17 & 4,48 & 4,33 & 4,00 & 3,87 & 3,46 & 4,19 & 4,04 & 3,94 & 0,41 \\
Restaurante ou lanchonete & 1,00 & 4,24 & 4,80 & 3,42 & 3,36 & 3,08 & 3,94 & 4,25 & 3,51 & 1,09 \\
Velocidade do acesso à internet & 2,00 & 3,13 & 3,83 & 3,80 & 2,58 & 2,54 & 3,92 & 3,29 & 3,13 & 0,66 \\
Laboratório de informática & 3,26 & 4,38 & 4,00 & 4,56 & 3,60 & 3,29 & 4,20 & 4,30 & 3,95 & 0,47 \\
Salas de aula & 3,16 & 4,48 & 3,33 & 4,45 & 3,64 & 3,51 & 3,78 & 4,11 & 3,81 & 0,46 \\
Biblioteca & 3,62 & 4,36 & 4,50 & 4,50 & 4,13 & 3,58 & 4,06 & 4,46 & 4,15 & 0,35
\end{tabular}


Universidade empreendedora: análise de estruturas e iniciativas de estímulo ao empreendedorismo

\begin{tabular}{|c|c|c|c|c|c|c|c|c|c|c|}
\hline $\begin{array}{l}\text { Laboratório de pesquisa } \\
\text { experimentação }\end{array}$ & e 2,89 & 4,40 & 4,17 & 4,55 & 3,71 & 3,26 & 4,09 & 4,39 & 3,93 & 0,56 \\
\hline Disponibilidade acesso à internet & 2,20 & 3,46 & 3,83 & 3,90 & 2,94 & 3,02 & 4,03 & 3,79 & 3,40 & 0,59 \\
\hline Média Geral por IES & 2,66 & 4,12 & 4,10 & 4,15 & 3,48 & 3,22 & 4,03 & 4,08 & 3,73 & - \\
\hline
\end{tabular}

Nota. Fonte: Dados da pesquisa.

Observa-se que os espaços abertos ou de convivência obtiveram uma média geral de 3,94, ou seja, as IES estão com uma boa avaliação dos discentes nesse quesito. Em relação aos restaurantes e lanchonetes, podem-se destacar as instituições X1, que apresentou a menor nota $(1,00)$, e a X3, que obteve uma média de 4,80, o que é considerada uma excelente nota.

Os tópicos "velocidade de acesso à internet" e "disponibilidade de acesso à internet" apresentaram as menores médias gerais, dentre todos os aspectos investigados acerca da infraestrutura da IES. Em um mundo "hiper" conectado, acesso e velocidade de internet serão elementos cada vez mais demandados por toda a comunidade acadêmica. Nesse sentido, a IES deve se preocupar em prover essa infraestrutura, uma vez que é um ponto de constante observação e bastante sensível no que diz respeito ao nível de satisfação.

Quando se trata de salas de aula, as instituições com boa infraestrutura nesse quesito, proporcionam mais conforto aos alunos, os quais tendem a ter um melhor desempenho no desenvolvimento de suas atividades (Satyro \& Soares, 2007). Os alunos de todas as IES pesquisadas consideraram esse quesito satisfatório, com média geral 3,81, chegando a, aproximadamente, $80 \%$ de satisfação.

Seguindo uma vertente de avaliações satisfatórias, a média geral para as bibliotecas foi 4,15, o que representa uma excelente nota. Destacam-se, negativamente, as IES X6 e X1, as quais ficaram com as menores avaliações, respectivamente, e se posicionaram abaixo da média.

Importante destacar que $34,44 \%$ dos alunos pesquisados não souberam dizer se a sua Instituição tem laboratório de pesquisa e experimentação e 15,93\% desconhecem a existência de laboratório de informática. Em relação aos laboratórios de pesquisas e experimentação, a instituição X1 ficou com uma média bem abaixo das demais. Segundo os autores Rodrigues e Tontini (1997), de acordo com seu modelo de transmissão de conhecimento e tecnologia, as pesquisas são ferramentas de extrema importância, principalmente para geração de conhecimentos e benefícios para a sociedade. Vale ressaltar que as instituições X4 e X2, respectivamente, obtiveram as maiores médias no referido quesito.

Por fim, ressalta-se que as instituições X4 e X2 apresentaram as maiores médias gerais, ou seja, na visão dos alunos sua infraestrutura é superior. 
Universidade empreendedora: análise de estruturas e iniciativas de estímulo ao empreendedorismo

No que concerne à perspectiva do aluno sobre a sua postura empreendedora, a tabela 4 apresenta a média das respostas, em uma escala de 1 a 5, em que 1 representa "discordo totalmente" e 5 "concordo totalmente".

Tabela 4

Postura empreendedora dos discentes

\begin{tabular}{l|c|c|c|c|c|c|c|c|c|c}
\hline Atributos/Instituições & $\mathbf{X 1}$ & $\mathbf{X 2}$ & $\mathbf{X 3}$ & $\mathbf{X 4}$ & $\mathbf{X 5}$ & $\mathbf{X 6}$ & $\mathbf{X} 7$ & $\mathbf{X 8}$ & $\begin{array}{c}\text { Média } \\
\text { por } \\
\text { atributo }\end{array}$ & $\begin{array}{c}\text { Desvio } \\
\text { Padrão }\end{array}$ \\
\hline Apoio a iniciativas empreendedoras & 2,74 & 2,93 & 2,83 & 3,60 & 3,54 & 2,95 & 3,06 & 3,54 & 3,15 & 0,33 \\
$\begin{array}{l}\text { Facilidade de comunicação das } \\
\text { ideias e sociabilidade }\end{array}$ & 3,39 & 3,85 & 3,83 & 3,50 & 3,69 & 3,54 & 3,11 & 3,68 & 3,57 & 0,23 \\
Curiosidade & 3,29 & 3,37 & 3,67 & 3,70 & 3,81 & 3,27 & 3,14 & 3,79 & 3,50 & 0,25 \\
Coragem para tomar risco & 2,55 & 2,59 & 2,00 & 3,30 & 3,37 & 2,39 & 3,03 & 3,61 & 2,85 & 0,52 \\
Pensamento inovador e criativo & 2,81 & 2,93 & 2,67 & 3,30 & 3,64 & 3,22 & 3,03 & 3,68 & 3,16 & 0,35 \\
Visão para oportunidades & 2,97 & 2,85 & 2,83 & 3,30 & 3,54 & 3,24 & 3,03 & 3,75 & 3,19 & 0,31 \\
Inconformismo com a realidade e & 2,90 & 2,96 & 3,17 & 3,60 & 3,26 & 3,27 & 2,69 & 3,79 & 3,21 & 0,34 \\
disposição para transformá-la & 2,95 & 3,07 & 3,00 & 3,47 & 3,55 & 3,13 & 3,01 & 3,69 & 3,23 & - \\
Média Geral por IES
\end{tabular}

Nota. Fonte: Dados da pesquisa.

Os alunos do curso de Administração das instituições X5, X8 e X4 se apresentaram como apoiadores de atividades empreendedoras, demonstrando que estão engajados com o ecossistema e que também se sentem responsáveis pela colaboração com a sua evolução. $\mathrm{O}$ atributo "facilidade de comunicação das ideias e sociabilidade" apresentou a maior média geral de 3,57, demonstrando a concordância dos discentes. Referente à coragem para tomar riscos, pode-se destacar a instituição X3, em que os alunos não consideram possuir essa característica empreendedora fazendo com que a média da instituição se torne inferior à das demais IES.

No que se refere à presença de pensamento inovador e criativo, os discentes das instituições X8 e X5, respectivamente, apresentaram as maiores médias. A respeito de visões para oportunidades, os alunos das instituições pesquisadas apresentaram uma média geral 3,19, ou seja, os alunos mantiveram uma postura neutra em relação à afirmativa proposta, o que pode transparecer que há espaço para se aproveitar melhor as lacunas apresentadas pelo mercado e pela sociedade. Mesmo comportamento neutro, com leve tendência à concordância, acontece com o atributo "inconformismo com a realidade e disposição para transformá-la". Tal postura é marcante em empreendedores e na realidade estudada, precisa ser trabalhada e encorajada nos discentes por toda a comunidade acadêmica.

De modo geral, destacam-se os discentes das instituições X8, X5 e X4, respectivamente, no que concerne à adoção de uma postura empreendedora, isto é, estão mais engajados com o REGMPE, Brasil-BR, V.6, No 1, p. 01-22, Jan./Abr.2021 www.revistas.editoraenterprising.net Página 14 
Universidade empreendedora: análise de estruturas e iniciativas de estímulo ao empreendedorismo

ecossistema, com as atividades relacionadas ao empreendedorismo, são mais arrojados, dinâmicos, inconformados com a realidade do que os das demais instituições pesquisadas.

Ressalta-se que as médias de todos os atributos tenderam à uma concordância "fraca", indicando que há uma lacuna a ser trabalhada no ambiente universitário, no que diz respeito à adoção de uma postura empreendedora por parte dos discentes.

Buscou-se conhecer também a percepção dos discentes em relação à postura empreendedora de seus professores. Observa-se na tabela 5 a média em relação às respostas computadas, considerando a escala de 1 a 5 , em que 1 "discordo totalmente" e 5 "concordo totalmente".

Tabela 5

Postura empreendedora dos docentes

\begin{tabular}{|c|c|c|c|c|c|c|c|c|c|c|}
\hline Atributos/Instituições & $\mathbf{X} 1$ & $\mathbf{X} 2$ & $\mathbf{X 3}$ & $\mathbf{X} 4$ & X5 & X6 & $\mathbf{X 7}$ & X8 & $\begin{array}{c}\text { Média } \\
\text { do } \\
\text { atributo }\end{array}$ & $\begin{array}{l}\text { Desvio } \\
\text { Padrão }\end{array}$ \\
\hline Apoio a iniciativas empreendedoras & 3,29 & 3,33 & 3,83 & 4,45 & 3,84 & 3,56 & 3,28 & 3,89 & 3,68 & 0,38 \\
\hline $\begin{array}{l}\text { Facilidade de comunicação das } \\
\text { ideias e sociabilidade }\end{array}$ & 3,81 & 4,11 & 4,00 & 4,35 & 3,93 & 4,49 & 3,31 & 4,21 & 4,03 & 0,34 \\
\hline Curiosidade & 3,61 & 3,48 & 3,67 & 4,40 & 3,77 & 4,00 & 3,25 & 4,21 & 3,80 & 0,36 \\
\hline Coragem para tomar risco & 3,10 & 2,30 & 3,67 & 4,50 & 3,64 & 3,20 & 3,36 & 4,00 & 3,47 & 0,61 \\
\hline Capacidade de realização & 3,35 & 3,11 & 3,50 & 4,65 & 3,83 & 3,68 & 3,36 & 4,00 & 3,69 & 0,45 \\
\hline Pensamento inovador e criativo & 3,52 & 3,04 & 3,83 & 4,40 & 3,83 & 4,20 & 3,44 & 4,07 & 3,79 & 0,42 \\
\hline Visão para oportunidades & 3,35 & 3,37 & 4,17 & 4,50 & 4,01 & 4,02 & 3,22 & 4,00 & 3,83 & 0,43 \\
\hline $\begin{array}{l}\text { Inconformismo com a realidade e } \\
\text { disposição para transformá-la }\end{array}$ & 3,55 & 3,56 & 4,17 & 4,40 & 3,72 & 3,76 & 2,81 & 4,00 & 3,74 & 0,45 \\
\hline Média Geral por IES & 3,45 & 3,29 & 3,86 & 4,46 & 3,82 & 3,86 & 3,25 & 4,05 & 3,75 & - \\
\hline
\end{tabular}

Nota. Fonte: Dados da pesquisa.

No atributo "apoio às iniciativas empreendedoras" pelos professores, a instituição X4 conseguiu um destaque positivo perante às demais. Em seu site oficial, esta instituição destaca que os alunos de Administração formados pela mesma possuem características empreendedoras para atuarem em diversos setores de empresas pública e privadas.

Referente à facilidade de comunicação das ideias e sociabilidade pelos professores, os alunos concordam que os docentes possuem uma boa transmissão de conhecimentos. No que tange à coragem para assumir riscos, característica do empreendedor, os professores obtiveram uma média geral de 3,47, ou seja, os alunos apresentaram uma visão neutra acerca da afirmação.

No quesito da capacidade de realização, os professores da instituição X8 apresentaram uma média acima das demais IES. Em relação ao pensamento inovador e criativo, os discentes REGMPE, Brasil-BR, V.6, No1, p. 01-22, Jan./Abr.2021 www.revistas.editoraenterprising.net Página 15 
Universidade empreendedora: análise de estruturas e iniciativas de estímulo ao empreendedorismo

da instituição X4 demonstraram concordar com a afirmativa, apresentando média 4,40, a qual ficou superior às demais IES.

A média obtida para o atributo "visão dos docentes para as oportunidades" foi de 3,83 , ou seja, pode-se considerar que os alunos acreditam, parcialmente, que os professores possuem uma postura visionária para identificar lacunas no mercado e na sociedade. Tal comportamento pode influenciar a postura do aluno, uma vez que este tem o professor como uma referência durante o seu processo de formação.

Com relação ao quesito "inconformismo com a realidade e sua disposição para transformá-la", a percepção dos alunos em relação aos professores da instituição X7 foi bem inferior às demais (média de 2,81), isto é, os discentes não acreditam que os professores possuem essa característica empreendedora.

Outra análise realizada nesta pesquisa foi a verificação de correlação entre as variáveis levantadas. Inicialmente foram calculadas todas as correlações e as que ficaram entre -0,50 e 0,50 não foram analisadas, pois apontam baixa correlação. Além disso, os fatores pertencentes à mesma dimensão também foram desconsiderados, por se tratar de resultados óbvios. Por exemplo, é bastante previsível que a "coragem para tomar risco" do aluno esteja altamente correlacionada com o seu "apoio a iniciativas empreendedoras". Vale destacar que não foi encontrada nenhuma correlação negativa inferior a -0,50. A partir dos filtros apontados, foram analisadas as correlações apresentadas na Tabela 6.

Tabela 6

Principais correlações entre os fatores levantados

\begin{tabular}{l|c|c|c|c|c}
\hline \multicolumn{1}{c|}{ Atributos } & $\begin{array}{c}\text { O ecossistema } \\
\text { universitário } \\
\text { influenciou } \\
\text { positivamente para } \\
\text { o desenvolvimento } \\
\text { da minha postura } \\
\text { empreendedora }\end{array}$ & $\begin{array}{c}\text { Visão para } \\
\text { oportuni- } \\
\text { dades (aluno) }\end{array}$ & $\begin{array}{c}\text { Capacidad } \\
\text { e de } \\
\text { Realização } \\
\text { (aluno) }\end{array}$ & $\begin{array}{c}\text { Coragem } \\
\text { para } \\
\text { tomar } \\
\text { risco } \\
\text { (aluno) }\end{array}$ & $\begin{array}{c}\text { Apoio a } \\
\text { iniciativas } \\
\text { empreende- } \\
\text { doras } \\
\text { (aluno) }\end{array}$ \\
\hline $\begin{array}{l}\text { Universidade oferece grade } \\
\text { curricular flexível }\end{array}$ & 0,5598 & 0,5285 & 0,5580 & 0,6042 & 0,5443 \\
$\begin{array}{l}\text { A grade curricular contribui } \\
\text { para o desenvolvimento de } \\
\text { competências } \\
\text { empreendedoras }\end{array}$ & 0,5221 & & & \\
$\begin{array}{l}\text { Capacidade de realização } \\
\text { (aluno) }\end{array}$ & 0,5149 & 0,5083 & & & \\
$\begin{array}{l}\text { Coragem para tomar risco } \\
\text { (aluno) }\end{array}$ & 0,5157 & & & \\
$\begin{array}{l}\text { Apoio a iniciativas } \\
\text { empreendedores (aluno) }\end{array}$ & & & &
\end{tabular}

REGMPE, Brasil-BR, V.6, №1, p. 01-22, Jan./Abr.2021 www.revistas.editoraenterprising.net Página 16 
Universidade empreendedora: análise de estruturas e iniciativas de estímulo ao empreendedorismo

\begin{tabular}{l|l|l|l|l}
$\begin{array}{l}\text { Coragem para tomar risco } \\
\text { (professor) }\end{array}$ & 0,5001 & 0,5479 & 0,5254 & \\
$\begin{array}{l}\text { Apoio a iniciativas } \\
\text { empreendedores (professor) }\end{array}$ & & 0,5130 & & 0,5062 \\
\hline
\end{tabular}

Nota. Fonte: Dados da pesquisa.

Os fatores que mais apresentaram correlações com outros foram "o ecossistema universitário influenciou positivamente para o desenvolvimento da minha postura empreendedora" e "minha Universidade oferece uma grade curricular flexível para que eu possa me engajar em atividades extracurriculares". Além da correlação entre si, o que indica que a grade curricular flexível e o ecossistema influenciador se relacionam, tais fatores também se correlacionaram, simultaneamente, com "capacidade de realização", "coragem para tomar risco" e "apoio a iniciativas empreendedoras", todos referentes aos alunos. Aqui surge a dúvida: o ecossistema e a grade curricular flexível atraem alunos com o perfil mais empreendedor ou os alunos com tais características estimulam esses aspectos na Universidade?

Outro ponto que merece destaque é que características empreendedoras dos docentes, como "coragem para tomar risco" e "apoio a iniciativas empreendedoras" se correlacionam com aspectos relacionados aos alunos, por exemplo "capacidade de realização", "coragem para tomar risco" e "apoio a iniciativas empreendedoras". Nesse ponto também é levantado um questionamento: os docentes estimulam o empreendedorismo nos alunos ou estes exigem dos professores uma postura mais inovadora?

Questões de cunho particular do tipo permanência na instituição e o grau de influência das instituições para uma possível matrícula também foram abordadas na pesquisa. Para a análise dessas questões foi utilizada a ferramenta denominada como "nuvem de palavras". Quando maior o tamanho da fonte da palavra, mais vezes esta foi citada como resposta à pergunta. A figura 3 apresenta os motivos que levam os discentes a permanecerem em uma IES. Figura 3

Motivos da permanência dos alunos na IES atual

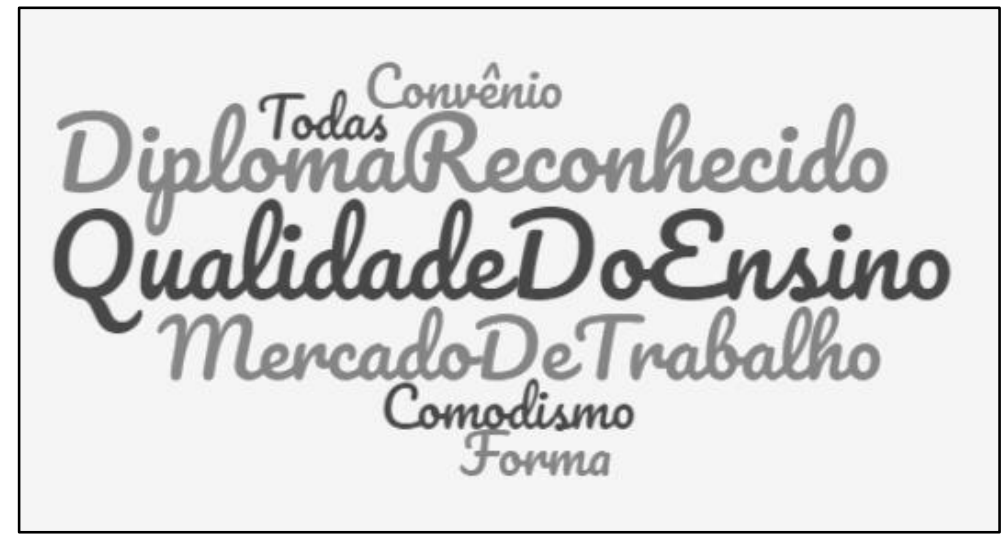

REGMPE, Brasil-BR, V.6, Nº1, p. 01-22, Jan./Abr.2021 www.revistas.editoraenterprising.net Página 17 
Universidade empreendedora: análise de estruturas e iniciativas de estímulo ao empreendedorismo

Nota. Fonte: Dados da pesquisa.

Nota-se que a qualidade do ensino, diploma reconhecido e mercado de trabalho são fatores que determinam a permanência dos discentes em sua respectiva instituição. As notas obtidas pelas IES nas avaliações do Ministério da Educação - MEC ou outras avaliações, como o Ranking de Universidade Folha - RUF, podem representar o motivo de permanência ou não do aluno na instituição, uma vez que atestam qualidade de ensino e sinalizam ao mercado a boa reputação da referida IES.

Os alunos das IES também foram questionados sobre a metodologia de ensino ideal e as respostas foram condensadas em uma "nuvem de palavras" (Figura 4).

Figura 4

Metodologia de ensino ideal

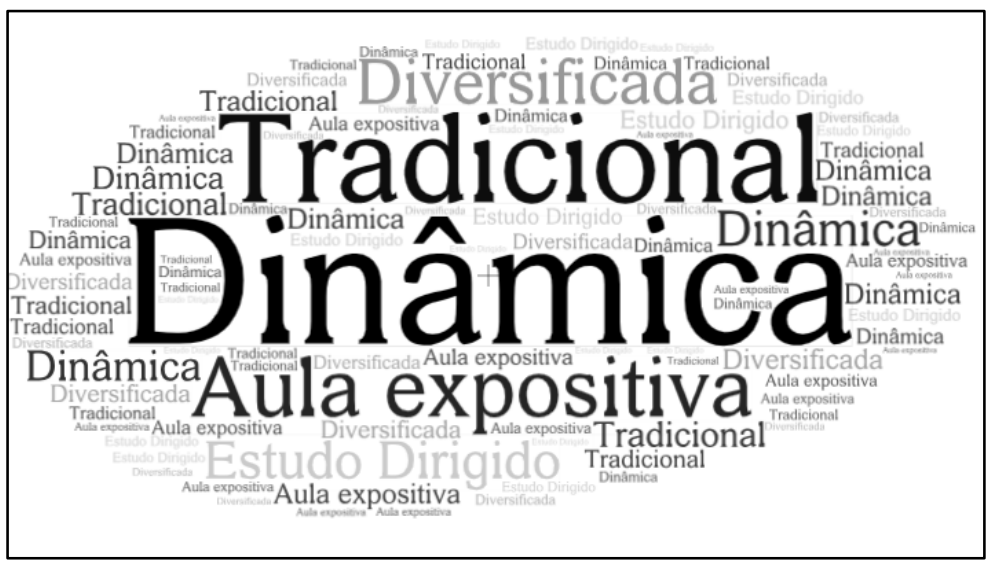

Nota. Fonte: Dados da pesquisa (2018).

Sob a ótica dos discentes, os mesmos acreditam que as aulas de caráter dinâmico influenciam positivamente ao empreendedorismo devido à sua forma de incentivar a aprendizagem. Segundo Rosa (2012), as aulas dinâmicas proporcionam aos alunos a deixarem de serem apenas ouvintes, interagindo-se com as atividades propostas e desenvolvendo uma melhor performance nas suas aprendizagens. Tal conclusão vai ao encontro do resultado apresentado na correlação do currículo flexível com outros fatores influenciadores da postura empreendedora.

\section{CONSIDERAÇÕES FINAIS}

Conforme estabelecido na introdução desse artigo, o objetivo da presente pesquisa foi, a partir da percepção dos alunos, levantar e comparar as estruturas e iniciativas de instituições de ensino superior de Belo Horizonte, que visam estimular o empreendedorismo. $\mathrm{O}$ REGMPE, Brasil-BR, V.6, No 1, p. 01-22, Jan./Abr.2021 www.revistas.editoraenterprising.net Página 18 
Universidade empreendedora: análise de estruturas e iniciativas de estímulo ao empreendedorismo

estabelecimento desse objetivo central se baseou na constatação de que, cada vez mais, as Universidades estão sendo estimuladas a criar estruturas internas de apoio a iniciativas empreendedoras discentes, adotar metodologias de ensino mais ativas, desenvolver ações extracurriculares para formação de competências empreendedoras e, além de tudo isso, estabelecer relações extramuros que facilitem a criação de novos negócios.

De maneira geral, os resultados mostraram que muito ainda há a ser feito para que os alunos percebam o envolvimento docente e da alta administração universitária no apoio e no estímulo ao empreendedorismo discente. No entanto, alguns aspectos dos resultados merecem ser destacados por indicarem que o processo de desenvolvimento de mentalidade empreendedora nos discentes não é consequência de esforço individual do docente ou da instituição, mas representa esforço conjunto dos atores institucionais. Por exemplo, a instituição X4 que apresentou a mais alta pontuação na infraestrutura universitária, também mostrou os melhores resultados nos quesitos postura empreendedora docente e discente.

Por outro lado, os dados mostraram que o envolvimento dos alunos na busca por conhecimento sobre empreendedorismo é pequeno, bem como as estratégias das universidades para divulgar e enfatizar a importância do desenvolvimento de habilidades empreendedoras para a atuação profissional dos discentes. Isso pode ser comprovado na medida em que mais de $50 \%$ dos entrevistados não souberam dizer se a IES em que estudam possuem incentivos ou apoio ao empreendedorismo. Ainda em relação à postura dos discentes, observou-se que alguns alunos não investem no desenvolvimento de competências empreendedoras, ou porque não acham importante ou porque não foram sensibilizados pela IES para a relevância dessa postura no mercado de trabalho.

Ao analisar a percepção dos discentes em relação à postura de seus professores frente ao tema empreendedorismo, observa-se que há uma expectativa de evolução na postura dos professores para uma melhor transmissão de seus conhecimentos, que resulte em incentivo à atitude empreendedora.

Os resultados da pesquisa apontam para a necessidade de que haja maior investimento por parte das IES em estruturas e projetos que estimulem a capacidade criadora e empreendedora dos discentes. Ao mesmo tempo, percebe-se que também o corpo docente deve buscar e adotar métodos que motivem os alunos a desenvolver competências empreendedoras, sinalizando, assim, com mais clareza, seu engajamento na formação de profissionais empreendedores. Em suma, cabe às IES, por meio de práticas efetivas, construírem uma cultura empreendedora, capaz de incentivar os discentes e docentes a investirem em seu REGMPE, Brasil-BR, V.6, No1, p. 01-22, Jan./Abr.2021 www.revistas.editoraenterprising.net Página 19 
Universidade empreendedora: análise de estruturas e iniciativas de estímulo ao empreendedorismo

desenvolvimento, alinhados às exigências das organizações, as quais habitam um ambiente de constantes mudanças.

Sugere-se para pesquisas futuras que o tema universidade empreendedora seja investigado em outras localidades do Brasil, no contexto de outros cursos, tais como os da área de tecnologia, e também na realidade das universidades federais.

\section{REFERÊNCIAS}

Audretsch, D. B. (2014). From the entrepreneurial university to the university for the entrepreneurial society. The Journal of Technology Transfer, 39(3), 313-321.

Audy, J. L. N. (2017). A inovação, o desenvolvimento e o papel da Universidade. Estudos avançados, 31(90), 75-87.

Andrade, R. F., \& Torkomian, A. L. V. (2001). Fatores de influência na estruturação de programas de educação empreendedora em Instituições de Ensino Superior. Anais do Encontro de estudos sobre empreendedorismo e gestão de pequenas empresas, Londrina, PR, Brasil.

Brasil. Ministério da Educação. Censo da educação superior 2016. Brasília, DF: Ministério da Educação, 2017. Recuperado em 15 jun. 2020 de http://portal.inep.gov.br/artigo//asset_publisher/B4AQV9zFY7Bv/content/mec-e-inep-divulgam-dados-do-censo-daeducacao-superior-2016/21206.

Bronoski, M. (2008). A intenção empreendedora no ambiente universitário: o caso Unicentro. Revista Capital Científico - Eletrônica, 6(1), 223-238.

Bussab, W. O.; Morettin, P. (2013). A. Estatística básica (9ª ed.). São Paulo: Saraiva.

Clark, B. R. (2003). Sustaining Change in Universities: Continuities in Case Studies and Concepts. Tertiary Education and Management, 9(2), 99- 116.

Dencker, A. de F. M. (2000). Métodos e técnicas de pesquisa em turismo. (4ª ed.). São Paulo: Futura.

Dornelas, J. C. A. (2016). Empreendedorismo: transformando ideias em negócios. (6 ${ }^{\mathrm{a}}$ ed.). São Paulo: Atlas.

Isenberg, D. (2011). The entrepreneurship ecosystem strategy as a new paradigm for economy policy: principles for cultivating entrepreneurship. The Babson Entrepreneurship Ecosystem Project.

Etzkowitz, H. (2003). Research groups as "quase-firms": the invention of the entrepreneurial university. Research Policy, 32, 109-121. 
Universidade empreendedora: análise de estruturas e iniciativas de estímulo ao empreendedorismo

Etzkowitz, H. (2004). The evolution of the entrepreneurial university. International Journal of Technology and Globalization, 1(1), 64-78.

Etzkowitz, H., \& Leydesdorff, L. (2000). The dynamics of innovation: from National Systems and "Mode 2" to a Triple helix of university-industry-government relations. Research Policy 29: 109-123.

Etzkowitz, H., \& Zhou, C. (2017). Triple helix: university-industry-government innovation and entrepreneurship. London: Routledge.

Martins, G. de A., \& Domingues, O. (2019). Estatística geral e aplicada. (6 ${ }^{\mathrm{a}}$ d.). São Paulo: Atlas.

Mason, C., \& Brown, R. (2014). Entrepreneurial ecosystems and growth oriented $\begin{array}{llllll}\text { entrepreneurship. } & \text { Recuperado em } & 15 & \text { jun } & 2020 & \text { de }\end{array}$ https://www.oecd.org/cfe/leed/Entrepreneurial-ecosystems.pdf.

Rodrigues, L. C., \& Tontini, G. (1997). A universidade empreendedora: geração e transferência de tecnologia. Revista de negócios, 2( 4), 37-49.

Rosa, A. B. (2012). Aula diferenciada e seus efeitos na aprendizagem dos alunos: o que os professores de biologia tem a dizer sobre isso? Monografia. Universidade Federal do Rio Grande do Sul, Porto Alegre. 2012.

Souza, A. M., \& Saraiva, L. A. S. (2009). Representações Sociais, Práticas e Desafios do ensino de Empreendedorismo na Graduação sob a Ótica dos docentes: um estudo de caso. Anais do Encontro de Ensino e Pesquisa em Administração e Contabilidade, Curitiba, PR, Brasil.

Satyro, N., \& Soares, S. (2007). A infraestrutura das escolas brasileiras de ensino fundamental: um estudo com base nos censos escolares de 1997 a 2005. Brasília: IPEA.

Serviço Brasileiro de Apoio às Micro e Pequenas Empresas. (2016). Empreendedorismo nas universidades brasileiras. Recuperado em 15 jun. 2020 de https://www.sebrae.com.br/sites/PortalSebrae/artigos/o-empreendedorismo-nasuniversidades-brasileiras,6ad3352450608510VgnVCM1000004c00210aRCRD.

Serviço Brasileiro de Apoio às Micro e Pequenas Empresas. Taxa de sobrevivência das empresas no brasil. Recuperado em 15 jun. 2020 de https://m.sebrae.com.br/sebrae/portal\%20sebrae/anexos/sobrevivencia_das_empresas_no_bra sil_2011.pdf.

Tornatzky, L. G., \& Rideout, E. C. (2014). Innovation U 2.0: reinventing university roles in a knowledge economy. Recuperado em $15 \quad$ jun. 2020 de 
Universidade empreendedora: análise de estruturas e iniciativas de estímulo ao empreendedorismo

https://www.researchgate.net/publication/289378647_Innovation_U_20_ReinventingUniversi ty_Roles_in_a_Knowledge_Economy.

Vergara, S. C. (2000). Projetos e relatórios de pesquisa em administração. (3ª ed.). São Paulo: Atlas.

Volles, B. K., Gomes, G., \& Parisotto, I. R. D. S. (2017). Universidade Empreendedora e Transferência de Conhecimento e Tecnologia. REAd. Revista Eletrônica de Administração, $23(1), 137-155$ 